UNIVERSITE DE LAUSANNE - FACULTE DE BIOLOGIE ET DE MEDECINE

\author{
HOPITAL OPHTALMIQUE JULES GONIN
}

SERVICE D'OPHTALMOLOGIE

\title{
DEEP SCLERECTOMY COMBINED WITH TRABECULECTOMY IN PEDIATRIC GLAUCOMA
}

\section{THESE}

préparée sous la direction du Professeur associé André Mermoud

et présentée à la Faculté de biologie et de médecine de

l'Université de Lausanne pour l'obtention du grade de

\section{DOCTEUR EN MEDECINE}

\author{
par \\ Michael FEUSIER

Médecin diplômé de la Confédération Suisse

Originaire de Saicourt (BE) et Perly-Certoux (GE)

Lausanne

2008 


\section{Résumé}

Ce travail porte sur l'étude rétrospective d'une série de jeunes patients opérés de glaucomes pédiatriques. Le but est d'évaluer le résultat au long cours d'une intervention chirurgicale combinant une sclérectomie profonde et une trabéculectomie (sclérectomie profonde pénétrante).

Durant la période de mars 1997 à octobre 2006, 28 patients on été suivis pour évaluer le résultat de cette chirurgie effectuées sur 35 yeux. Un examen ophtalmologique complet a été pratiqué avant la chirurgie, 1 et 7 jours, puis $1,2,3$, 4, 6, 9, 12 mois, enfin tous les 6 mois après l'opération. Les critères d'évaluation du résultat postopératoire sont: les changements de pression intraoculaire, le traitement antiglaucomateux adjuvant, le taux de complication, le nombre de reprises chirurgicales, l'erreur de réfraction, la meilleure acuité visuelle corrigée, l'état et le diamètre de la cornée.

L'âge moyen est de $3.6 \pm 4.5$ ans et le suivi moyen de $3.6 \pm 2.9$ ans. La pression intraoculaire préopératoire de $31.9 \pm 11.5 \mathrm{mmHg}$ baisse de $58.3 \%(p<0.005)$ à la fin du suivi. Sur les 14 patients dont l'acuité visuelle a pu être mesurée, $8(57.1 \%)$ ont une acuité égale ou supérieure à $5 / 10^{\circ}, 3(21.4 \%)$ une acuité de $2 / 10^{\circ}$ après intervention. Le taux de succès cumulatif complet à 9 ans est de $52.3 \%$, le succès relatif $70.6 \%$. Les complications menaçant la vision (8.6\%) ont été plus fréquentes dans les cas de glaucome réfractaire.

Pour conclure la sclérectomie profonde combinée à une trabéculectomie est une technique chirurgicale développée afin de contrôler la pression intraoculaire dans les cas de glaucomes congénitaux, juvéniles et secondaires. Les résultats intermédiaires sont encourageants et prometteurs. Les cas préalablement opérés avant cette nouvelle technique ont cependant un pronostic moins favorable. Le nombre de complications menaçant la vision est essentiellement lié à la sévérité du glaucome et au nombre d'interventions préalables. 
Deep Sclerectomy combined with Trabeculectomy in Pediatric

\section{Glaucoma}

Michael Feusier, MD*; Sylvain Roy, MD, PhD*; André Mermoud, MD

Glaucoma Unit, Jules Gonin Eye Hospital, University of Lausanne

Av de France 15, $\mathrm{CH}-1004$ Lausanne

*: These authors have equally contributed to this work.

None of the authors have any financial or proprietary interests in any product, method or material presented in this paper

This paper has been presented as a poster at the 2007 World Glaucoma Congress in Singapore and at the 2008 ARVO Convention in Fort Lauderdale

This manuscript contains 1 video clip

This work was not supported by any funding

Address for correspondence:

Dr. Sylvain Roy

Glaucoma Unit

Jules Gonin Eye Hospital

Av. De France 15

$\mathrm{CH}-1004$ Lausanne

Phone :+4121 6268224

Fax :+4121626 8246

Email: sylvain.roy@epfl.ch 


\section{Abstract}

Purpose: To evaluate the outcomes of combined deep sclerectomy and trabeculectomy (penetrating deep sclerectomy) in pediatric glaucoma.

Design: Retrospective, non-consecutive, non-comparative, interventional case series.

Participants: Children suffering from pediatric glaucoma who underwent surgery between March 1997 and October 2006 were included in this study.

\section{Methods:}

A primary combined deep sclerectomy and trabeculectomy was performed in 35 eyes of 28 patients. Complete examinations were performed before surgery, postoperatively at 1 and 7 days, at $1,2,3,4,6,9,12$ months and then every 6 months after surgery.

Main Outcome Measures: Surgical outcome was assessed in terms of intraocular pressure (IOP) change, additional glaucoma medication, complication rate, need for surgical revision, as well as refractive errors, best corrected visual acuity (BCVA), and corneal clarity and diameters.

\section{Results:}

The mean age before surgery was $3.6 \pm 4.5$ years, and the mean follow-up was $3.5 \pm$ 2.9 years. The mean preoperative IOP was $31.9 \pm 11.5 \mathrm{mmHg}$. At the end of followup, the mean IOP decreased by 58.3\% (p<0.005), and from 14 patients with available BCVA 8 patients (57.1\%) achieved $0.5(20 / 40)$ or better, $3(21.4 \%) 0.2$ (20/100), and $2(14.3 \%) 0.1(20 / 200)$ in their better eye. The mean refractive error (spherical equivalent) at final follow-up visits was $+0.83 \pm 5.4$. Six patients $(43 \%)$ were affected by myopia. The complete and qualified success rates, based on a 
cumulative survival curve, after 9 years were $52.3 \%$ and $70.6 \%$, respectively $(p<0.05)$. Sight threatening complications were more common $(8.6 \%)$ in refractory glaucomas.

\section{Conclusions:}

Combined deep sclerectomy and trabeculectomy is a surgical technique developed to control IOP in congenital, secondary and juvenile glaucomas. The intermediate results are satisfactory and promising. Previous classic glaucoma surgeries performed before this new technique had less favourable results. The number of sight threatening complications is related to the severity of glaucoma and number of previous surgeries.

\section{Key words:}

Infant, Newborn; Filtering surgery; Glaucoma; Glaucoma/surgery; Trabeculectomy 


\section{Introduction}

Congenital and pediatric glaucomas are difficult to handle for ophthalmologists. Only early recognition and treatment can help physicians in preserving sight for these young patients. ${ }^{1,2}$

As early as 1869 congenital glaucoma was identified as a likely cause for the specific features accompanying the classic ocular triad: epiphora, photophobia, and blepharospasm. The exact definition of congenital glaucoma may vary among several authors reporting on this entity. ${ }^{1,2,3}$ Congenital glaucoma most generally defines a glaucoma disease occurring as early as at birth and extending upon the $3^{\text {rd }}$ year of life. Following that period in life glaucoma is then defined as a juvenile glaucoma which may extend up to 15-year old children. The Schaffer-Weiss classification encompasses three forms of developmental glaucoma: the primary infantile glaucoma; the glaucoma associated with developmental disorders; and the acquired glaucoma.

Many efforts have been developed for detecting congenital glaucoma which require careful and comprehensive examinations of the child's eye under general anesthesia. ${ }^{4,5}$ This procedure allows a correct examination of the anatomy of the anterior segment including the cornea, the iris and the iridocorneal angle, the lens and the fundus, and precise measurement of the intraocular pressure (IOP). There is a general consensus that congenital glaucoma is best treated by surgery and that medical treatment is not a long term solution for controlling IOP over time..$^{3,6,7}$ 
Several surgical procedures have been advocated to restore the aqueous humor pathway and to lower the elevated IOP. 1, 2, 3 Goniotomy, first described by Barkan in the 1930's, consists in severing the trabeculum and putative Barkan's membrane which is thought to impede easy aqueous humor egress. After this procedure the aqueous humor is drained through the trabeculum aperture. ${ }^{1,8}$ The trabeculotomy was proposed later as a means to open the trabeculum from the external side of the anterior segment to facilitate the outflow of aqueous humor. 9, 10 A classic trabeculectomy was also considered a surgical option for removing the obstacle to the aqueous humor pathway in congenital glaucoma. ${ }^{11-14}$

The deep sclerectomy, described in the 1990's, was initially indicated for the surgical treatment of primary open angle glaucoma and other forms of secondary open angle glaucomas in adult patients. ${ }^{15}$ Deep sclerectomy was proposed to decrease the number of postoperative complications as well as to reduce the size of the subconjunctival filtering bleb as compared to the trabeculectomy. The opening of the trabeculo-Descemet's membrane and the basal iridectomy have been proposed further in cases where Schlemm's canal appeared to be absent or when aqueous humour outflow was deemed insufficient, to suppress the need for a secondary goniopuncture. ${ }^{16,17}$

In this paper we present the results of primary combined deep sclerectomy and trabeculectomy for the treatment for congenital and pediatric glaucomas in patients with up to a 9-year follow up period. 


\section{Patients and Methods}

\section{Patients}

This retrospective, non-consecutive, non-comparative case series took place at the Glaucoma Unit of the Ophthalmology Department, University of Lausanne, Switzerland. Between March 1997 and October 2006, 35 eyes of 28 patients with pediatric glaucoma underwent primary combined deep sclerectomy and trabeculectomy. Children operated on were suffering from primary congenital glaucoma, developmental disorders, or secondary glaucoma associated with ocular diseases. The patients, non consecutive cases, were enrolled in this study after formal approval by the Ethical Committee of the University of Lausanne. Preference for this technique compared to other filtering surgery was given based on the surgeon (AM) clinical experience and actual clinical status. Each patient's legal representative received a comprehensive explanation about the surgery, its implications and signed a written informed consent prior to the surgery.

Pediatric glaucoma was defined by an elevated IOP, an enlarged corneal diameter and/or cornea cloudiness, Descemet tears or Haab's striae, and/or abnormal anterior chamber findings under gonioscopy, as assessed by an experienced glaucoma specialist (AM). Some patients were temporarily under medical therapy (one or more antiglaucoma medications) and/or had previous failed filtering surgeries. In eyes with a previous failed filtering surgery, the quadrant used to perform the combined surgery was different from the initial surgery. The motivation for this was to minimize interferences with possible conjunctival scarring or remodeling reaction from the former surgery. 
The clinical outcome assessment included refractive errors, best corrected visual acuity (BCVA), corneal status and diameters, axial length, gonioscopy, intraocular pressure (IOP), rates of surgical complications and success.

\section{Data Recorded Preoperatively}

Each patient underwent a comprehensive ophthalmic examination that included measurement of the distance BCVA, when practical, using Snellen charts at 6 meters, anterior segment slit lamp biomicroscopy including corneal parameters (diameter, pachymetry, clarity, presence of Haab's strias), fundus examination with optic disc evaluation, axial length, automated refraction, two IOP measurement readings with the Goldmann applanation tonometer or the Perkins tonometer for tonometry under general anesthesia.

\section{Surgical procedures}

All operations were performed by one experienced ophthalmic surgeon (AM) under general anesthesia, as shown in online video (video clip 1 available at http://aaojournal.org). The technique consisted in a limbus-based conjunctiva opening, followed by the creation of a superficial scleral flap measuring 5 by $5 \mathrm{~mm}$, one third full sclera thickness. In case of previous external failed filtering surgery (i.e. trabeculectomy) the conjunctiva opening and the scleral flap were performed in a site free of tissue scarring. A sponge soaked with Mitomycin C $(0.2 \mathrm{mg} / \mathrm{ml})$ was applied for about 1 minute in eyes with previous filtering surgery to prevent recurrence of failure and in eyes with secondary glaucoma due to uveitis or Sturge-Weber to prevent scarring of the filtering bleb. A deep scleral flap measuring 4 by $4 \mathrm{~mm}$, leaving only a very thin layer of sclera with a barely visible choroidal underneath was 
then dissected down to the Schlemm's canal (in primary congenital and developmental glaucomas Schlemm's canal was often difficult to clearly identify) and gently cut at the level of the trabeculo-descemet's membrane. This dissection provided an intrascleral space to draw off aqueous humor to the drainage channels. At that point the classical deep sclerectomy procedure was modified and a small portion of the trabeculum (about 3 to $4 \mathrm{~mm}$ ) was removed to perform the trabeculectomy. This modification has been proposed to avoid the need for further laser goniopuncture as it is the case for non-penetrating deep sclerectomy. A cylindrical collagen implant $($ Aquaflow $(\mathbb{B})$ was secured onto the deep scleral bed to act as a space maintainer for the scleral space. The superficial scleral flap was sutured with several Nylon 10-0 single knots. The degree of tightness on the scleral flap was assessed by a balanced salt solution injected in the anterior chamber through a side port. The filtration was titrated to allow a gentle and continuous flow egress. Viscoelastic was injected into the anterior chamber through a paracenthesis. After an efficient filtration was achieved, the conjunctiva was closed with a 8-0 Vicryl@ running suture. Postoperative treatment consisted in topical application of tobramycin and dexamethasone $5 x /$ day for one month, followed by ketorolac TID for 2 months.

\section{Criteria for success}

Successful outcomes were divided into two groups, criterion A and criterion B. In order to meet criterion $\mathrm{A}$, an IOP without medication greater than $6 \mathrm{mmHg}$ but $<$ $18 \mathrm{mmHg}$ was required. In order to meet criterion $\mathrm{B}$, an IOP without medication less than or equal to $15 \mathrm{mmHg}$ was required. Qualified success used the same criteria with or without medication. Failure occurred when IOP was higher than $18 \mathrm{mmHg}$ 
despite maximally tolerated medication, and/or further glaucoma surgery was required, or the sight was lost. Postoperative bleb management and fibrosis modulation using the needling technique, with or without Mitomycin C (MMC) injection, were not a criterion for failure. IOP data were collected at the last follow-up to determine success.

\section{Postoperative follow-up}

Intraocular pressure, mean number of medications, best corrected visual acuity (when possible), refractive errors, and complications were recorded preoperatively on two separate days, at 1 and 7 days, at $1,2,3,4,6,9,12$ months and then every 6 months after surgery or more often when required by the clinical situation. The last follow-up data consisted of the mean of two separate day measurements.

Any complication was recorded and was defined as either a major or a minor complication based on the clinical significance and importance overtime. Evaluation of the complications was based on the surgeon's clinical experience. The minor complications were hyphema, shallow anterior chamber and choroidal detachment. Hyphema was present when blood collection was seen in the anterior chamber. Anterior chamber depth was clinically assessed under slit lamp examination and was considered shallow when iridocorneal touch in the periphery was noticed. Choroidal detachment was observed under indirect ophthalmoscopy. All these complications were considered minor as they either resolved spontaneously or required minimal surgical revision. The major complications were endophthalmitis, total choroidal detachment or phthisis bulbi. 
When the filtering bleb, at any postoperative visit, was encysted or showed signs of fibrosis leading to an increase in IOP $>20 \mathrm{mmHg}$, subconjunctival injections of MMC were administered. The subconjunctival injections consisted of $0.05-0.1 \mathrm{ml}$ of a $0.02 \%$ MMC solution injected beneath the filtering bleb under topical anaesthesia.

\section{Materials}

The collagen implant is a cylindrical device (length: $4 \mathrm{~mm}$; diameter: $1 \mathrm{~mm}$ ) made from lyophilized porcine scleral collagen (Aquaflow (B) Staar Surgical AG, Nidau, Switzerland).

\section{Statistical analysis}

Data are expressed as the mean \pm standard deviation SD, (range, min-max). Results were analyzed using Student t-test for parametric data (IOP), Wilcoxon signed-rank test for non-parametric data (BCVA, number of medication) and KaplanMeier survival curves for the success rate calculation. Results were considered significant when $p<0.05$. With an $n$-value of 35 we have at least $90 \%$ power to detect differences in IOP before and after surgery of at least $3 \mathrm{mmHg}$ with a SD of $3 \mathrm{mmHg}$ at a 2-sided alpha level of 0.05 . 


\section{Results}

\section{Patient Demographics}

A primary combined deep sclerectomy and trabeculectomy was performed in 35 eyes of 28 patients. The mean age of the patients before surgery was $3.6 \pm 4.5$ years ( 3 days- 13 years). Seventeen patients $(60.7 \%)$ had primary congenital glaucoma (23 eyes), whereas 6 patients $(21.4 \%)$ suffered from developmental disorders. Four (14.2\%) of these patients had a Sturge-Weber syndrome (4 eyes), 1 (3.6\%) a neurofibromatosis ( 1 eye), and $1(3.6 \%)$ a Cogan syndrome (1 eye). Five patients $(17.9 \%)$ had secondary glaucoma. These resulted from uveitis and aphakia in 2 eyes of the same patient $(7.1 \%)$, aphakia and vitrectomy in 2 eyes of two patients (7.1\%), uveitis in 1 eye of one patient (3.5\%) and late onset primary juvenile glaucoma after trauma at the age of 13 years in 1 eye of one patient (3.5\%). The 4 cases of aphakia resulted from congenital cataract removal (phacoemulsification) prior to entering this study. All data are set on table 1. The mean follow-up was $3.5 \pm$ 2.9 years ( 3 months-9.1 years). For one patient the surgery was performed 3 days postnatal, but he died 2.5 years later for medical reasons not related to the eye disease. Five patients ( 6 eyes) had previous glaucoma surgeries at a mean time 2.5 \pm 1.4 years before the combined surgery presented here; trabeculectomy was performed on 5 eyes of four patients, and goniotomy on 1 eye of one patient.

Intraocular pressure

The mean preoperative IOP was $31.9 \pm 11.5 \mathrm{mmHg}(16-53 \mathrm{mmHg})$. Fifteen eyes $(42.8 \%)$ were under antiglaucoma medication prior to undergoing filtering surgery. The mean preoperative number of medications per patient was $1.1 \pm 1.7$ (05). These medications were prescribed to lower the IOP after the congenital 
glaucoma had been confirmed based on the clinical examination but prior to glaucoma surgery. At the final follow-up visits, the mean IOP was $13.3 \pm 5.6 \mathrm{mmHg}$ (2-31 $\mathrm{mmHg})$, thus representing a decrease of $18.6 \mathrm{mmHg}(-58.3 \%)$ between preoperative and postoperative data, $(p<0.005)$, (figures 1 and 2) (table 4). The mean number of medications per patient (table 2) went down to $0.4 \pm 0.7(0-3)$ at the completion of the follow-up, $(p<0.005)$. Nine eyes $(25.7 \%)$ required 1 to 3 antiglaucoma treatments to control IOP (figure 3).

\section{Cornea parameters}

Mean preoperative horizontal corneal diameters were $13.1 \pm 1.4 \mathrm{~mm}(10-17$ $\mathrm{mm})$. Twelve eyes (34.3\%) had corneal edema, and 11 eyes (31.4\%) showed Haab striation at the initial clinical examination. One year after surgery, mean horizontal corneal diameters were $13.2 \pm 1.3 \mathrm{~mm}(12-16 \mathrm{~mm})$. There was no significant difference in corneal diameters before and after surgery. Only one eye (2.8\%) presented persistent corneal clouding, and 11 eyes (31.4\%) were still showing Haab's striae 12 months after surgery. The improvement in corneal clearing was statistically significant $(p<0.001)$

Gonioscopy

On gonioscopy at the preoperative examination, 10 eyes $(28.5 \%)$ shown iridocorneal angle dysgenesis, and 2 eyes (5.6\%) had an angle closure configuration (less than 2 in Schaffer scale).

Visual acuity 
The data on visual acuity (figure 4) were available for 14 patients $(50.0 \%)$. From 14 patients with available BCVA 8 patients (57.1\%) achieved $0.5(20 / 40)$ or better, $3(21.4 \%) 0.2(20 / 100)$, and $2(14.3 \%) 0.1(20 / 200)$ in their better eye (table 2). One patient (7.2\%) had severe visual impairment with finger counting at 1 meter.

\section{Refractive errors}

The data on refractive errors were available for 17 eyes (48.5\%). The mean refractive error (spherical equivalent SE) in dioptre $D$ at the final follow-up visits was $+0.83 \pm 5.4(-7+15.75$ D). From these 17 eyes, $6(35.3 \%)$ were myopic with a mean SE of $-3.8 \pm 1.6(-2.5-7$ D). Seven $(41.2 \%)$ were hyperopic with a mean SE of $+5.7 \pm$ $6.6(0-16 \mathrm{D})$, from which 4 were suffering from aphakia. Four eyes $(23.5 \%)$ were emmetropic with a SE of zero. Astigmatism was present in 13 eyes (76.5\%) with a mean cylindrical correction of $-2.2 \pm 1.4(-0.5-5 \mathrm{D})$ (table 2).

\section{Success rate}

Based on cumulative survival analysis, complete success rate using criterion A (> $6 \mathrm{mmHg}$ but $\leq 18 \mathrm{mmHg}$ ) was $52.3 \%$. Using criterion B (> $6 \mathrm{mmHg}$ but $\leq 15$ $\mathrm{mmHg}$ ), the success rate was $42.1 \%$ (figure 5). Qualified success rates with criterion A was $70.6 \%$ and with criterion B $57.6 \%$, respectively. From the 26 eyes with surgical success, $19(76.1 \%)$ had no prior surgery. For the primary congenital glaucoma, 6 eyes out of 23 were classified as a failure due to the need for further surgery or lost of sight. For the developmental disorder glaucoma, 2 eyes out of 6 failed, and for the secondary glaucoma, 1 eye out of 6 was considered as a failure due to the need of vitrectomy following vitreous prolapse. From these 9 failures, 4 eyes (44.4\%) underwent a mean of $2.8(1-5)$ previous filtering surgeries. 


\section{Complications}

From the 35 eyes operated, $3(8.6 \%)$ had severe complications that resulted in phthisis bulbi leading eventually to enucleation. Two of these eyes had several previous failed filtering surgeries with advanced glaucoma (mean $C / D=0.8$ ), but none had adjunctive treatments such as postoperative MMC injection. One case (neurofibromatosis) was suffering from endophthalmitis 1 week after the surgery (no previous filtering procedure) and despite vigorous intravitreal injections of antibiotics following pars plana vitrectomy the eye was lost. One eye (primary congenital glaucoma with congenital cataract) had uncontrolled IOP (> $26 \mathrm{mmHg}$ ) after the filtering surgery (phacoemulsification, vitrectomy, secondary intraocular lens implantation, trabeculectomy, were performed from 1 month to 6 years after birth) and laser cyclophotocoagulation was performed 4 times (from month 4 to month 15 postoperative) before ending in phthisis bulbi. The last eye (primary congenital glaucoma initially treated by trabeculectomy at the age of 1 year) had elevated IOP ( $>28 \mathrm{mmHg}$ ) and an implantation of a Baerveldt tube was performed 4 months after the combined surgery. Despite initial good IOP control, the tube was replaced 18 months later due to tube migration but unfortunately severe choroidal detachment and aqueous misdirection occurred resulting in phthisis bulbi within 4 years.

Intra-operative MMC (14 eyes) was given both in eyes with previous filtering surgery $(n=6)$ to prevent recurrence of failure and in eyes with secondary glaucoma due to uveitis $(n=3)$ or Sturge-Weber syndrome and neurofibromatosis $(n=5)$. Postoperative application $(n=7)$ was given when IOP was $>20 \mathrm{mmHg}$. The mean time between surgery and MMC application was $32.4 \pm 17.8$ days. Four eyes $(57 \%)$ had an IOP < $15 \mathrm{mmHg}$ at last follow-up control without medication, 3 with one or two 
antiglaucoma medications. Five eyes had primary congenital or juvenile glaucoma, and 2 had Sturge-Weber syndrome.

Nine eyes $(25.7 \%)$ had transient complications, from which $6(17.2 \%)$ required further surgical revision (table 3). The 3 eyes that didn't required surgical revision had a good outcome at last visit with an IOP $<15 \mathrm{mmHg}$ without medication. From the 6 eyes undergoing secondary surgery, the vitreous prolapse (in aphakia and previous vitrectomy) underwent successful anterior vitrectomy with secondary intraocular lens implantation with an IOP around $16 \mathrm{mmHg}$ at last visit; the iris prolapse (juvenile glaucoma) was reduced and IOP was stable at $12 \mathrm{mmHg}$ without medication; the cataract (in primary glaucoma) was removed uneventfully and the IOP was controlled below $18 \mathrm{mmHg}$ with medications. The three cases of hypertony (2 primary glaucoma, 1 developmental glaucoma) were reoperated and a surgical revision was performed. The IOP was stable $<16 \mathrm{mmHg}$ without medication. 


\section{Discussion}

The goal in the efficient management of pediatric glaucoma is to rapidly lower the IOP and to keep it low for a long term prospective. To achieve this challenging task, it is important to correctly understand the anatomopathological reasons leading to impairment in the drainage of the aqueous humor.

The overall success after filtering surgery in pediatric glaucoma has been reported to be variable, depending on the surgical technique and the severity of the disease. ${ }^{1}$ It is generally accepted that the chances for good surgical success are the highest when only one surgery is required, and that successive procedures reduce the success rate. ${ }^{6,18}$

In this study we report the results on 35 eyes of 28 patients operated by combined deep sclerectomy and trabeculectomy in pediatric glaucoma. The IOP was lower than $18 \mathrm{mmHg}$ for all but 5 eyes (84\%) 3.5 years after surgery, and from the 26 successful eyes 19 (76.1\%) which had no prior surgeries. This compares favorably with Mc Pherson and Berry who reported a $83 \%$ success rate after external trabeculectomy on 23 eyes. ${ }^{18}$ Mullaney et al reported a $78 \%$ success rate using a combined trabeculoctomy-trabeculectomy technique in children's eyes without anterior segment anomalies. ${ }^{14}$ Deep sclerectomy alone might prove to be challenging in achieving satisfactory IOP control in refractory congenital glaucoma. Lüke et al in a small series of 8 young patients mentioned a specific risk profile associated with deep sclerectomy in surgery for refractory congenital glaucoma. ${ }^{19}$ Conversion from deep sclerectomy to trabeculectomy was performed in four eyes and supplemented by a trabeculotomy in two eyes out of ten. Despite effective IOP 
reduction all eyes were ultimately classified as failures. Yet, in a study of a similar technique in 12 eyes, Tixier et al found no intraoperative or immediate postoperative complications. ${ }^{20}$ The success rate at 10 months was $75 \%$, IOP was elevated in 3 eyes and one of them underwent re-operation. The difference between these two studies lies in the fact that Lüke was reporting on patients having a history of previous glaucoma surgery while in the series citied by Tixier only 3 of 12 eyes had two interventions before deep sclerectomy. Roche et al have evaluated the results of nonpenetrating external trabeculectomy for primary congenital glaucoma on 43 eyes of 27 consecutive patients with primary $\mathrm{CG}^{17}$ Of the 43 eyes, 13 required conversion to trabeculectomy because of insufficient filtration (9), apparent absence of Schlemm's canal (3) or accidental perforation (1). In the remaining 30 eyes, the success rate was $93 \%$ with a mean postoperative IOP of $10.8 \mathrm{mmHg}$. The long-term follow-up is questionable in respect to the need for further goniopuncture. Cillino et al have compared the long-term effects of low-dosage mitomycin $C(\mathrm{MMC})$ in both deep sclerectomy and trabeculectomy. ${ }^{21}$ At the 48 months end-point either procedure controlled IOP efficaciously, a low-dosage MMC can be considered a mild enhancement of deep sclerectomy IOP-lowering effect.

The reason for proposing modifications from the original deep sclerectomy is to avoid the complications reported by Lüke. The aim of performing deep sclerectomy is to reduce the size of the sub-conjunctival filtering bleb generally found after classic trabeculectomy. The idea is to bring the aqueous humor into the scleral space, and to enhance growing of intrascleral drainage pathway. ${ }^{22}$ The reduction in the size of the sub-conjunctival filtering bleb can diminish the risks, complications and postoperative treatments related to larger blebs. In a controlled case study in 
adults, Nd:YAG laser goniopuncture was performed in $51 \%$ of all patients after deep sclerectomy. ${ }^{16}$ Performing laser goniopuncture in children might prove challenging. In order to avoid the need of such laser goniopuncture, we have included the trabeculectomy in the surgical technique. This would prevent the thin trabeculoDescemet's membrane from limiting egress of aqueous humor after surgery. The new surgical technique, as a filtering procedure in pediatric glaucoma, takes advantage of the direct by-pass from the anterior chamber to a reservoir in the sclera. From that newly created space aqueous humor is drained through 3 different pathways: the subconjunctival space, the intrascleral route, and the subchoroidal space. In trabeculectomy the main route goes though the subconjunctival space, resulting in a significant filtering bleb, and the two latter routes are not present due to the lack of a reservoir created during deep sclerectomy. The deep sclerectomy with external trabeculectomy combines the advantages of routing the aqueous humor thought these 3 pathways, thus reducing the height of the conjunctival bleb, and the direct removal of the main obstacle to aqueous egress at the level of the trabeculum. This modified technique is therefore no longer a non-penetrating procedure, such as for a standard non-penetrating deep sclerectomy, but it takes benefit from the deep sclerectomy approach in respect to the aqueous humor drainage. We have favored this procedure over goniotomy or trabeculectomy for the congenital, secondary and juvenile glaucoma patients in order to give them both the best chance to efficiently lower the IOP on the long term while reducing the risk of sight threatening complications. A significant number (34\%) of eyes presented with a cornea oedema which prevented a clear view of the angle for a safe goniotomy. For this reason this technique was not selected in this case series. Deep sclerectomy in adults has proven to be a safe an efficient procedure providing stable and reasonable control of 
IOP at long-term follow-up in a 96 month study. ${ }^{16}$ Based on these results, we have included the deep sclerectomy with external trabeculectomy at first line of treatment in our algorithm for handling congenital and juvenile glaucomas.

Measurements of the IOP in children often requires general anesthesia and the effects of anesthetics may increase or decrease IOP with changing outcomes over time, depending on the level of anesthesia. ${ }^{5}$ Halothane was reported to significantly lower IOP. ${ }^{4}$ Controversy still exists as to the extent to which IOP is reduced after general anesthesia with gas anesthetics. In a study comparing IOP measurements of infants under both awake and sedated conditions, Quigley found that the IOP in the awake state was similar to that after ketamine sedation, whereas gas anesthetics similar to sevoflurane lowered IOP. ${ }^{7}$ Blumberg et al, in a paper reporting the effects of sevoflurane, a gas anesthetic and ketamine, found that the IOP was significantly lowered by about $7 \mathrm{mmHg}$ during sevoflurane anesthesia compared to ketamine alone. ${ }^{5}$ We have segregated the IOP measurements in two groups, one including data obtained under topical anesthesia, and the other one for data obtained under general gas anesthesia (Figures 1 and 2). We have observed that IOP measurements under gas anesthesia were lower than that under an awake state with topical anesthesia, thus confirming the remarks from previous studies about the lowering effects of gas anesthetics.

The limitations of this study are the retrospective non-comparative design, the small number of developmental and secondary glaucoma, the variability in the IOP measuring technique due to the general anesthesia, and the lack of visual acuity data in half of the patients. The patient selection was based on the surgeon's 
experience and this could have induced a bias in the indication for such surgery. Approximately $1 / 3$ of eyes with corneal edema or myopia were considered a relatively mild disease when compared to some studies in the literature. ${ }^{3,12,13}$ The strength of our study lies in the fact that the same technique was used by the same surgeon for all surgeries, and in the number of eyes operated, which compares favourably to other studies. ${ }^{3}$

In conclusion the combined deep sclerectomy and trabeculectomy is a surgical technique recently developed to control IOP in congenital, secondary and juvenile glaucomas. The intermediate results are satisfactory and promising in lowering the IOP over time. The best results are found when this surgery is the first filtering procedure, which reduces the complications related to the trabeculectomy only. Unfortunately when other glaucoma surgeries are performed before this technique the outcomes are less favourable. The results indicate that the number of sight threatening complications is related to the severity of the glaucoma and the number of previous failed surgeries. Great care should be given in indicating the correct surgical technique in order to avoid further surgery, thus reducing the risk of complications and surgical failure. 


\section{Acknowledgements}

We wish to present our thanks to Mr Tyler Thacher at the Lausanne Swiss Federal Institute of Technology for the careful reading of this text. 


\section{References}

1. Shaffer RN. Prognosis of goniotomy in primary infantile glaucoma (trabeculodysgenesis). Trans Am Ophthalmol Soc 1982;80:321-5.

2. deLuise VP, Anderson DR. Primary infantile glaucoma (congenital glaucoma). Surv Ophthalmol 1983;28:1-19.

3. Mandal AK, Gothwal VK, Bagga $\mathrm{H}$, et al. Outcome of surgery on infants younger than 1 month with congenital glaucoma. Ophthalmology 2003;110:1909-15.

4. Ausinsch B, Munson ES, Levy NS. Intraocular pressures in children with glaucoma during halothane anesthesia. Ann Ophthalmol 1977;9:1391-4.

5. Blumberg $\mathrm{D}$, Congdon $\mathrm{N}$, Jampel $\mathrm{H}$, et al. The effects of sevoflurane and ketamine on intraocular pressure in children during examination under anesthesia. Am J Ophthalmol 2007;143:494-9.

6. Haas J. Principles and problems of therapy in congenital glaucoma. Invest Ophthalmol 1968;7:140-6.

7. Quigley HA. Childhood glaucoma: results with trabeculotomy and study of reversible cupping. Ophthalmology 1982;89:219-26.

8. Barkan O. Technique of goniotomy. Arch Ophthalmol 1938;19:217-21.

9. Harms H, Dannheim R. Trabeculotomy-results and problems. Adv Ophthalmol 1970;22:121-131.

10. Akimoto $M$, Tanihara $\mathrm{H}$, Negi A, Nagata $M$. Surgical results of trabeculotomy ab externo for developmental glaucoma. Arch Ophthalmol 1994;112:1540-4.

11. Marrakchi S, Nacef L, Kamoun N, et al. Results of trabeculectomy in congenital glaucoma [in French]. J Fr Ophtalmol 1992;15:400-4.

12. Elder MJ. Combined trabeculotomy-trabeculectomy compared with primary trabeculectomy for congenital glaucoma. Br J Ophthalmol 1994;78:745-8.

13. Dureau P, Dollfus H, Cassegrain C, Dufier JL. Long-term results of trabeculectomy for congenital glaucoma. J Pediatr Ophthalmol Strabismus 1998;35:198-202.

14. Mullaney PB, Selleck C, Al-Awad A, et al. Combined trabeculotomy and trabeculectomy as an initial procedure in uncomplicated congenital glaucoma. Arch Ophthalmol 1999;117:457-60.

15. Fjodorov SN, loffe DI, Ronkina TI. Deep sclerectomy:technique and mechanism of a new glaucomatous procedure. Glaucoma 1984;6:281-283. 
16. Shaarawy T, Mansouri K, Schnyder C, et al. Long-term results of deep sclerectomy with collagen implant. J Cataract Refract Surg 2004;30:1225-31. 17. Roche O, Beby F, Parsa A, et al. Nonpenetrating external trabeculectomy for congenital glaucoma: a retrospective study. Ophthalmology 2007;114:1994-9. 18. McPherson SD Jr, Berry DP. Goniotomy vs external trabeculotomy for developmental glaucoma. Am J Ophthalmol 1983;95:427-31.

19. Lüke C, Dietlein TS, Jacobi PC, et al. Risk profile of deep sclerectomy for treatment of refractory congenital glaucomas. Ophthalmology 2002;109:1066-71. 20. Tixier J, Dureau P, Becquet F, Dufier JL. Deep sclerectomy in congenital glaucoma: preliminary results [in French]. J Fr Ophtalmol 1999;22:545-8. 21. Cillino S, Di Pace F, Casuccio A, et al. Deep sclerectomy versus trabeculectomy with low-dosage mitomycin C: four-year follow-up. Ophthalmologica 2008;222:81-7. 22. Delarive T, Rossier A, Rossier S, et al. Aqueous dynamic and histological findings after deep sclerectomy with collagen implant in an animal model. $\mathrm{Br} \mathrm{J}$ Ophthalmol 2003;87:1340-4. 
Table 1. Demographics

\begin{tabular}{|c|c|}
\hline Demographics & No $(\%)$ \\
\hline Number of eyes & 35 \\
\hline Male / Female $(n=28)$ & $15(53.6) / 13(46.4)$ \\
\hline $\begin{array}{l}\text { Age at surgery (mean years } \pm S D \text { ) } \\
\text { Range }\end{array}$ & $\begin{array}{l}3.6 \pm 4.5 \\
3 \text { days- } 13 \text { years }\end{array}$ \\
\hline Caucasians / African & $27 / 1$ \\
\hline Diagnosis ( $n=$ patients) & No of eyes (\%) \\
\hline Primary congenital glaucoma $(n=17)$ & $23(65.8)$ \\
\hline Developmental disorders glaucoma $(n=6)$ & $6(17.1)$ \\
\hline Secondary glaucoma $(n=5)$ & $6(17.1)$ \\
\hline Total previous surgeries $(n=8)$ & $10(28.6 \%)$ \\
\hline Filtering surgeries $(n=5)$ & $6(17.1 \%)$ \\
\hline $\begin{array}{l}\text { Follow-up (mean years } \pm \text { SD) } \\
\text { Range }\end{array}$ & $\begin{array}{l}3.5 \pm 2.9 \\
3 \text { months-9.1 years }\end{array}$ \\
\hline $\begin{array}{l}\text { Preoperative IOP (mean } \mathrm{mmHg} \pm \mathrm{SD} \text { ) } \\
\text { Range }\end{array}$ & $\begin{array}{l}31.9 \pm 11.5 \\
16-53\end{array}$ \\
\hline $\begin{array}{l}\text { Preoperative medications per patient (mean } \pm \text { SD) } \\
\text { Range }\end{array}$ & $\begin{array}{l}1.1 \pm 1.7 \\
0-5\end{array}$ \\
\hline $\begin{array}{l}\text { Horizontal corneal diameters (mean } \mathrm{mm} \pm \mathrm{SD} \text { ) } \\
\text { Range }\end{array}$ & $\begin{array}{l}13.1 \pm 1.4 \\
10-17\end{array}$ \\
\hline Corneal oedema & $12(34.3)$ \\
\hline Cornea Haab striation & $11(31.4)$ \\
\hline Angle dysgenesis & $10(28.5 \%)$ \\
\hline $\begin{array}{l}\text { Snellen preoperative BCVA (mean } \pm \text { SD) }(n=14) \\
\text { Range }\end{array}$ & $\begin{array}{l}0.43 \pm 0.32 \\
\text { FC- } 0.9\end{array}$ \\
\hline $\begin{array}{l}\text { Ultrasound axial length (mean } \mathrm{mm} \pm \mathrm{SD} \text { ) } \\
\text { Range }\end{array}$ & $\begin{array}{l}23.3 \pm 3.7 \\
19-32\end{array}$ \\
\hline $\begin{array}{l}\text { Optic disc C/D } \\
\text { Range }\end{array}$ & $\begin{array}{l}0.62 \pm 0.25 \\
0.25-1.0\end{array}$ \\
\hline
\end{tabular}

Legends: BCVA: best corrected visual acuity; C/D: cup/disc ratio; FC: finger counting at 1 meter; IOP: intraocular pressure; SD: standard deviation 
Table 2. Postoperative results

\begin{tabular}{|l|l|}
\hline Results & No $(\%)$ \\
\hline Postoperative IOP (mean $\mathrm{mmHg} \pm \mathrm{SD})$ & $13.3 \pm 5.6$ \\
Range & $2-31$ \\
\hline Postoperative medications per patient (mean $\pm \mathrm{SD})$ & $0.4 \pm 0.7$ \\
Range & $0-3$ \\
\hline Horizontal corneal diameters (mean $\mathrm{mm} \pm \mathrm{SD}) \dagger$ & $13.2 \pm 1.3$ \\
Range & $12-16$ \\
\hline Corneal oedema & $1(2.8)$ \\
\hline Cornea Haab's striae & $11(31.4)$ \\
\hline Snellen postoperative BCVA (mean $\pm \mathrm{SD})(\mathrm{n}=14)$ & $0.66 \pm 0.36$ \\
Range & $\mathrm{FC}-1.0$ \\
\hline Spherical equivalent refractive error (mean $\mathrm{D} \pm \mathrm{SD})(\mathrm{n}=17)$ & $+0.83 \pm 5.4$ \\
Range & $-7+15.75$ \\
\hline Ultrasound axial length (mean mm $\pm \mathrm{SD})$ & $23.8 \pm 2.7$ \\
Range & $20-32$ \\
\hline Number of superficial flap suture (mean $\pm \mathrm{SD})$ & $4.4 \pm 2.4$ \\
Range & $0-8$ \\
\hline Number of perioperative MMC application & $14(40)$ \\
\hline Duration of perioperative MMC application (mean sec $\pm \mathrm{SD})$ & $60 \pm 34$ \\
Range & $30-120$ \\
\hline
\end{tabular}

Legends: BCVA: best corrected visual acuity; D: dioptre; FC: finger counting at 1 meter; IOP: intraocular pressure; MMC: Mitomycin C; SD: standard deviation †: One year after surgery. 
Table 3. Complications

\begin{tabular}{|l|l|}
\hline Results & No (\%) \\
\hline Major complications & $3(8.6)$ \\
\hline Phthisis bulbi & $2(5.7)$ \\
\hline Endophthalmitis & $1(2.9)$ \\
\hline Minor complications & $9(25.7)$ \\
\hline Corneal ulceration & $1(2.9)$ \\
\hline Hypotony* & $1(2.9)$ \\
\hline Choroidal detachment & $1(2.9)$ \\
\hline Vitreous prolapse in the anterior chamber† & $1(2.9)$ \\
\hline Iris incarceration† & $1(2.9)$ \\
\hline Hypertony† & $3(8.6)$ \\
\hline Cataract† & $1(2.9)$ \\
\hline & \\
\hline Number of postoperative MMC application & $7(20)$ \\
\hline
\end{tabular}

Legends: MMC: Mitomycin C. *Hypotony was defined as IOP(intraocular pressure) $\leq$ $6 \mathrm{mmHg} . \dagger$ : Required further surgery. 
Table 4. Mean IOP over time

\begin{tabular}{|l|l|}
\hline $\begin{array}{l}\text { Follow-up months } \\
\text { (number of patients) }\end{array}$ & $\begin{array}{l}\text { Mean IOP } \mathrm{mm} \mathrm{Hg} \\
\pm \mathrm{SD}\end{array}$ \\
\hline $12(35)$ & $13.8 \pm 5.4$ \\
\hline $24(32)$ & $15.2 \pm 2.2$ \\
\hline $36(25)$ & $14.8 \pm 2.2$ \\
\hline $48(21)$ & $13.7 \pm 3.4$ \\
\hline $60(18)$ & $15.6 \pm 4.8$ \\
\hline $72(12)$ & $13.6 \pm 4.7$ \\
\hline $84(11)$ & $14.7 \pm 9.6$ \\
\hline $96(11)$ & $14.6 \pm 4.9$ \\
\hline $108(10)$ & $13.3 \pm 5.6$ \\
\hline
\end{tabular}

Legends: IOP: intraocular pressure; SD: standard deviation 


\section{Legends for figures}

Figure 1. Scattered graph of the mean pre-and postoperative intraocular pressure (IOP) $(n=32)$

Figure 2. Box-plots of the mean intraocular pressure (IOP) for topical (top) and general anesthesia (bottom) tonometry measurements $(n=35)$

Figure 3. Mean number of antiglaucoma medication per patient before and after surgery $(n=35)$

Figure 4. Scattered graph of the mean pre-and postoperative Snellen best corrected visual acuity (BCVA) $(n=14)$

Figure 5. Kaplan-Meier survival curve showing the failure rate. Top: Success criterion A ( $\leq 18 \mathrm{mmHg})$. Bottom: Success criterion B (( $\leq 15 \mathrm{mmHg})$. 
Figure 1.

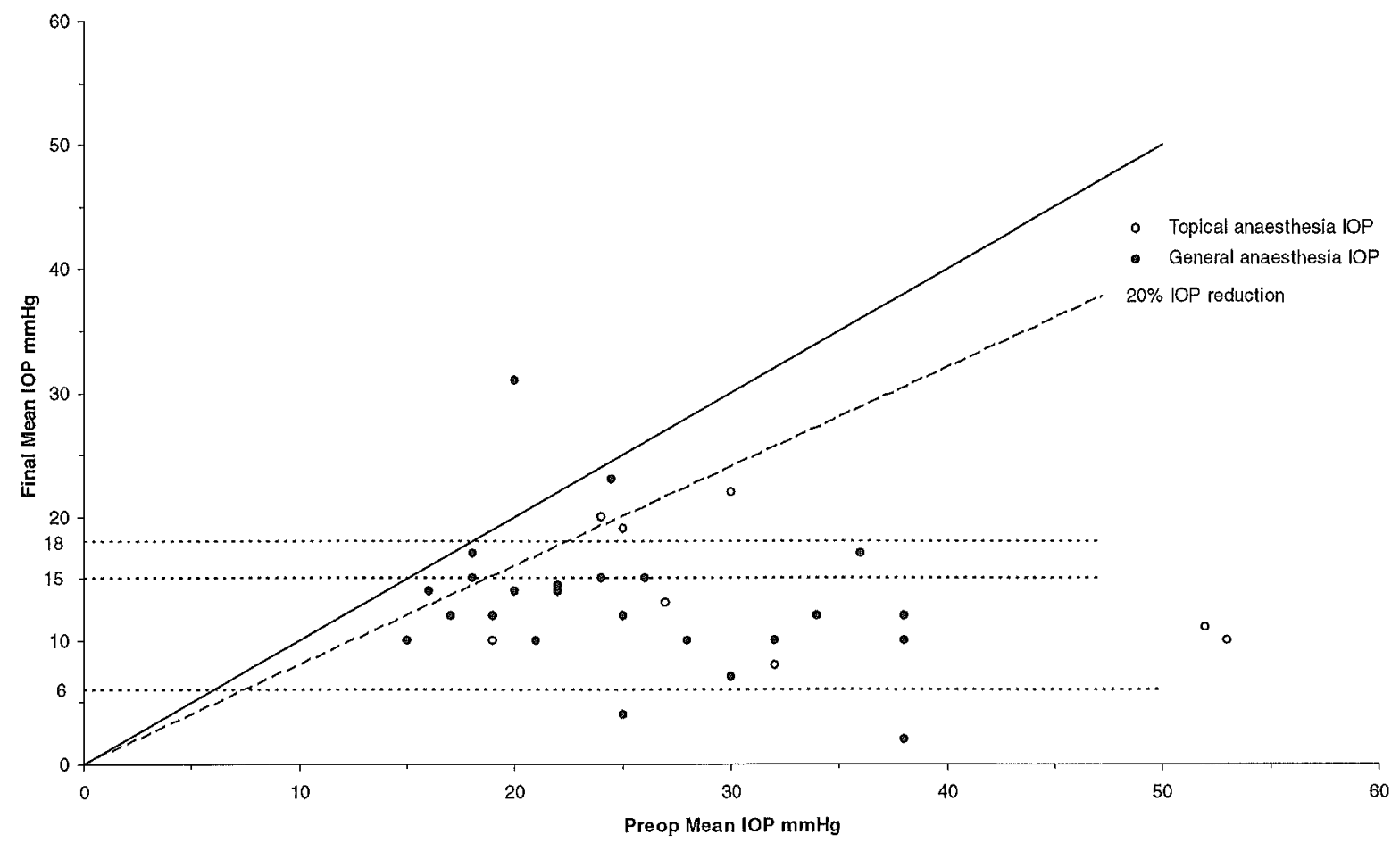


Figure 2.
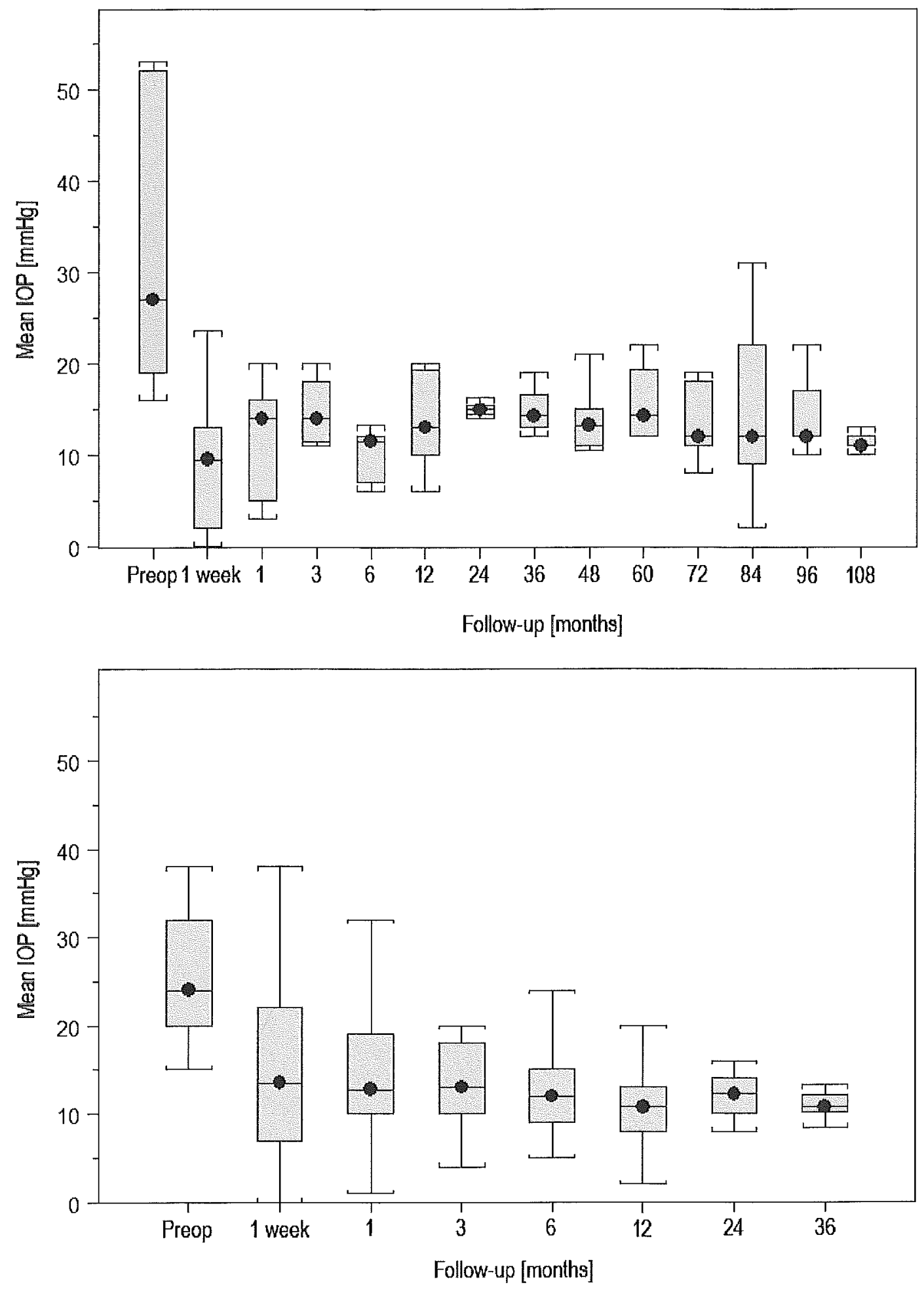
Figure 3.

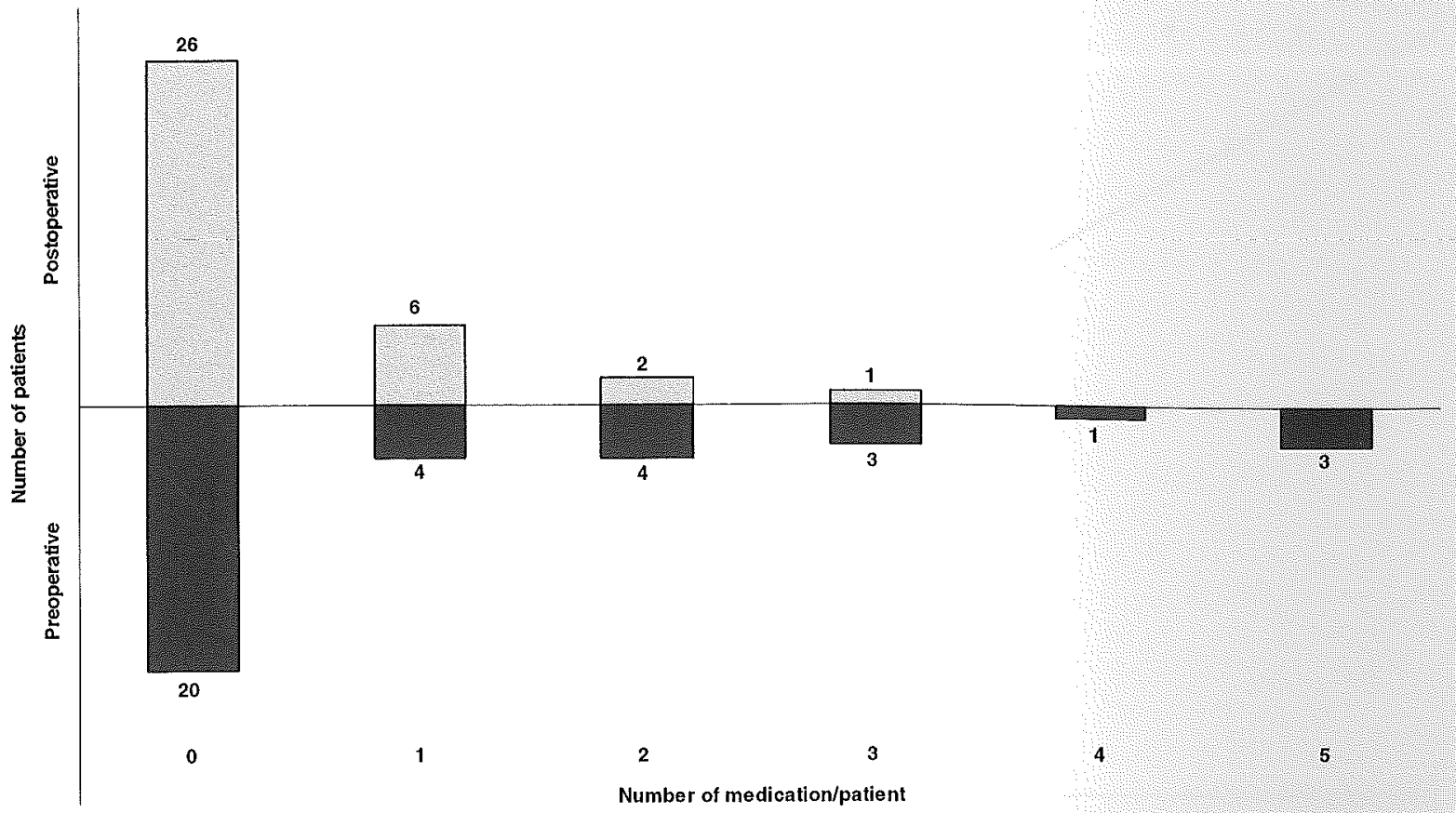


Figure 4.

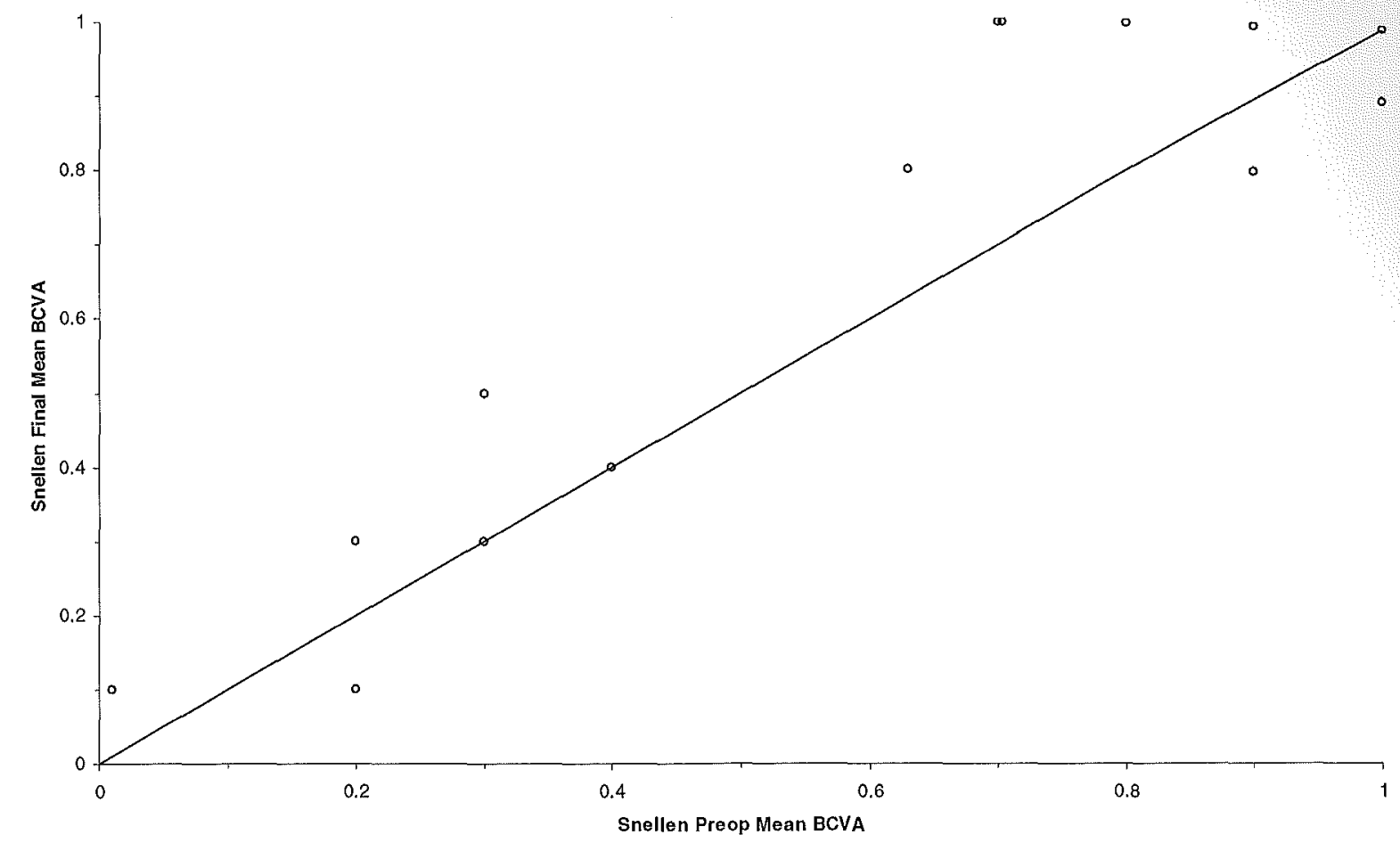


Figure 5.
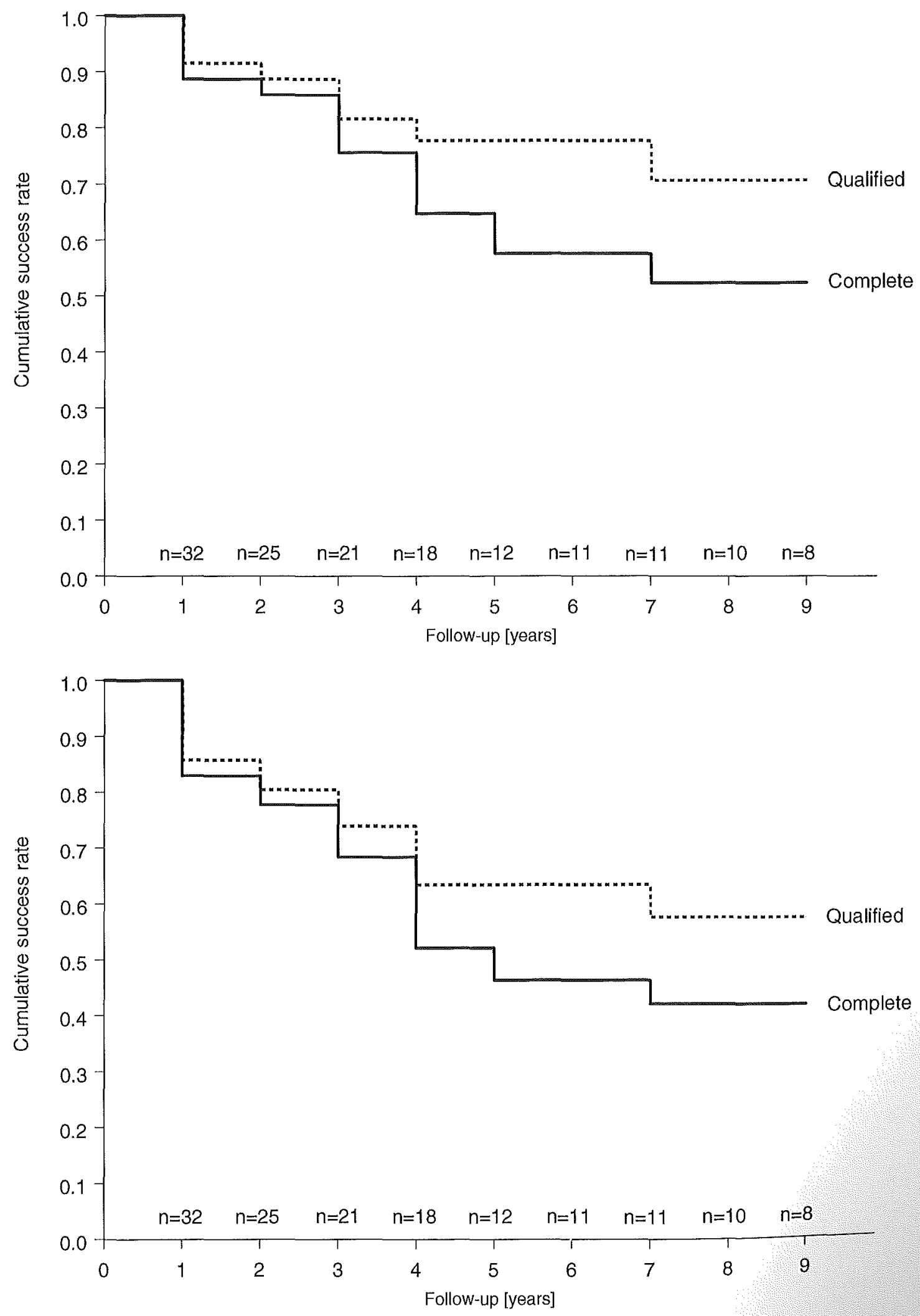